\title{
Occurrence of Mycobacterium spp. in ornamental fish
}

\author{
Krzysztof Puk ${ }^{1, A-D \oplus}$, Leszek Guz ${ }^{1, A, C, E-F \oplus \infty}$ \\ ${ }^{1}$ Department of Fish Diseases and Biology, Faculty of Veterinary Medicine, University of Life Sciences, Lublin, Poland \\ A - Research concept and design, B - Collection and/or assembly of data, C - Data analysis and interpretation, \\ $D$ - Writing the article, E-Critical revision of the article, F- Final approval of article
}

Puk K, Guz L. Occurrence of Mycobacterium spp. in ornamental fish. Ann Agric Environ Med. 2020; 27(4): 535-539. doi: 10.26444/aaem/114913

\begin{abstract}
Introduction and objective. Fish mycobacteriosis is a chronic granulomatous disease caused by several species of bacteria from the genus Mycobacterium, described as nontuberculous mycobacteria (NTM). The most important species causing fish mycobacterioses are $M$. chelonae, M. fortuitum, and M. marinum. Mycobacteria infecting fish also include zoonotic pathogens. M. marinum is the cause of most cases of fish-related mycobacterial infection in humans. The disease occurs more frequently in workers in the fishing industry, people whose hobbies involve water activities, and aquarists. The aim of the present study was to examine the occurrence of different species of mycobacteria in freshwater ornamental fish.

Materials and method. The occurrence of Mycobacterium spp. in freshwater ornamental fish was studied from January 2015 - December 2016. Material isolated from skin scrapings, contents of the digestive tracts, and internal organs of ornamental fish was stained with Ziehl-Neelsen (ZN) and inoculated on Lowenstein-Jensen medium. All isolates found positive by ZN were identified by amplification of the gene encoding the Hsp65 protein. A total of 408 samples obtained from 136 ornamental fish from 36 species were tested.

Results. Using the culture method Mycobacterium was isolated from 69 fish (50.1\%) and 99 samples (24.3\%). Sequence analysis of gene fragments coding for the Hsp65 protein of 99 isolates revealed occurrence of 13 species of mycobacteria: M. abscessus, M. chelonae, M. fortuitum, M. gordonae, M. marinum, M. mucogenicum, M. neoaurum, M. peregrinum, M. salmoniphilum, M. saopaulense, $M$. senegalense, $M$. septicum, and M. szulgai.

Conclusions. The obtained results indicate a significant role of ornamental fish as a source of mycobacteria which are potentially dangerous,especially to humans.
\end{abstract}

\section{- Key words}

Mycobacterium spp., ornamental fish, prevalence, public health

\section{INTRODUCTION}

Fish mycobacteriosis is caused by several species of bacteria from the genus Mycobacterium. Mycobacterial infections are found in both freshwater and marine fish worldwide [1]. The most important species causing fish mycobacterioses are $M$. chelonae, $M$. fortuitum, and M. marinum [2]. Other species isolated from fish include $M$. abscessus, M. arupense, $M$. avium, M. chesapeaki, M. conceptionense, $M$. flavescens, M. gordonae, M. haemophilum, M. kansasii, M. monteforense, $M$. neoaurum, $M$. nonchromogenicum, $M$. parascrofulaceum, M. peregrinum, M. pseudoshottsii, M. salmoniphilum, $M$. saopaulense, $M$. scrofulaceum, $M$. senegalense, $M$. septicum, M. shottsii, M. simiae, M. terrae, M. szulgai, M. triviale, $M$. triplex, and $M$. xenopi $[3,4,5,6,7,8,9,10,11,12,13]$.

Fish mycobacteriosis is a chronic disease, often associated with non-specific clinical symptoms. Diseased fish exhibit lethargy, loss of appetite, emaciation, ascites, scale loss, abnormal behaviour, pigment changes, exophthalmia, dermal ulceration, and spinal defects. At necropsy, characteristic grey or white nodules in the muscles and internal organs can be observed [1].

Treatment of fish mycobacteriosis is difficult, costconsuming, long-lasting, and dangerous to subjects in contact with diseased fish. For this reason, treatment is carried out in

Address for correspondence: Leszek Guz, Department of Fish Diseases and Biology Faculty of Veterinary Medicine, University of Life Sciences, Lublin, Poland E-mail: leszek.guz@up.lublin.pl

Received: 08.10.2019; accepted: 28.11.2019; first published: 09.12.2019 cultures of high value. Liquidation is usually recommended of the affected stock and disinfection of the tanks [14].

Mycobacteria infecting fish also include zoonotic pathogens that can cause both localized and disseminated infections in man. The population at risk includes people who are exposed to aquatic environments, mainly workers in the fishing industry and aquarists $[1,15,16,17]$. The infection usually occurs by contact through wounds caused by infected fish or during the handling of the aquariums, such as cleaning or changing the water [15]. Currently, M. marinum causes the most cases of fish related infections in man [15]. However, aquarists should be aware of the zoonotic potential of any of the NTM $[16,17]$.

Acid fast bacilli (AFB) smear microscopy, despite its lack of specificity, is the first step in the diagnosis of mycobacterial infections [15]. However, due to the difference in clinical significance of NTM, species identification of mycobacterial isolates is necessary. Traditional methods, such as biochemical tests, fail to provide a precise identification of closely related NTM species [18]. Furthermore, molecular methods, such as hybridization DNA probe assays, $16 \mathrm{~S}$ rRNA gene multiplex PCR, or PCR restriction fragment length polymorphism analysis (PRA) for identification of nontuberculous mycobacteria, might fail to distinguish closely related species [19]. For this reason, gene sequencing is considered the gold standard for identification of Mycobacterium species [20]. Gene encoding the $65-\mathrm{kDa}$, a heat shock protein ( $h s p 65$ ) is present in all mycobacterial species and used widely for identification of NTM to species level because of its 
interspecies variability, compared to some other conserved genes such as $16 \mathrm{~S}$ rRNA or $r p o B[20,21]$.

The zoonotic potential and the great importance of mycobacteriosis for fish breeders highlight the need to characterize the diversity of mycobacteria in ornamental fish.

\section{OBJECTIVE}

The aim of the presented study was to examine the occurrence of different species of mycobacteria in diseased freshwater ornamental fish in Poland.

\section{MATERIALS AND METHOD}

From January 2015 - December 2016, 136 diseased ornamental fish sent from private aquaria and pet shops to the laboratory of the Department of Fish Diseases and Biology, Faculty of Veterinary Medicine, University of Life Sciences in Lublin, Poland, were examined for mycobacteria. Fish were euthanized using an overdose of ethyl 3-aminobenzoate methanesulfonate (Sigma Aldrich, USA). Skin, gut content, and visceral organs (spleen, liver, and kidney) were taken from each fish. If sampling the gut content was not possible due to their small size, entire guts were subjected to the cultivation protocol. Before decontamination, smears of homogenized biological material were prepared, stained with Ziehl-Neelsen $(\mathrm{ZN})$ and observed under 100x (oil immersion) objective lens for the detection of AFB. A negative report was not given untill at least 100 fields had been examined. For mycobacterial culture, the samples were mixed with an equal volume of a $5 \%$ oxalic acid solution and incubated for $15 \mathrm{~min}$. Afterwards, the samples were centrifuged at 3,000 $\mathrm{g}$ for $15 \mathrm{~min}$. The pellets were washed twice in sterile phosphate buffered saline and inoculated onto one egg Lowenstein-Jensen (LJ) media at $25^{\circ} \mathrm{C}$ and $37^{\circ} \mathrm{C}$. The slants were checked daily for 2 months. Clearly visible colonies were examined according to their morphology and confirmed by microscopic examination after $\mathrm{ZN}$ staining of smears prepared from the colonies. AFB positive colonies were identified by the amplification of a 439 bp mycobacterial DNA fragment of the $h s p 65$ gene using primers Tb11 (5'-ACCAACGATGGTGTGTCCAT-3') and Tb12 (5'-CTTGTCGAACCGCATACCCT-3') [21]. PCR reactions were performed in a thermal cycler (MJ-Mini, BioRad, USA) with the amplification profile: initial denaturation at $94^{\circ} \mathrm{C}$ for $10 \mathrm{~min}$, followed by 45 cycles at $94^{\circ} \mathrm{C}$ for $1 \mathrm{~min}$, $60^{\circ} \mathrm{C}$ for $1 \mathrm{~min}, 72^{\circ} \mathrm{C}$ for $1 \mathrm{~min}$, and a final extension at $72^{\circ} \mathrm{C}$ for $5 \mathrm{~min}$. The PCR products were analysed by $1 \%$ agarose gel electrophoresis. DNA fragments of expected length were purified using Gel-Out Extraction Kit (A\&A Biotechnology Gdynia, Poland), according to the manufacturer's instructions, and subjected to direct sequencing at a DNA sequencing core facility (Genomed S.A., Warsaw, Poland). DNA sequences were aligned with the available $h s p 65$ gene sequences from the National Centre for Biotechnology Information Gene Bank for Mycobacterium spp. using the MEGA6 software.

\section{RESULTS}

During the study, a total of 136 fish were excamined. AFB $\mathrm{ZN}$-stained specimens provided positive microscopic results in $15.44 \%(n=21)$ of the examined fish. Culture methods provided positive results in 69 examined fish (50.74\%) and in 99 of the total 408 examined samples $(24.26 \%)$. All isolates were identified using sequencing of the $h s p 65$ gene. The identity of mycobacterial isolates according to fish species are shown in Table 1. Carassius auratus, Danio rerio, Poecilia reticulate, Xiphophorus maculates, Paracheirodon innesi, Pterophyllum scalare, and Poecilia sphenops were the most commonly sampled fish. M. marinum, M. gordonae, M. peregrinum, and $M$. chelonae were the most frequently identified mycobacteria in the above-mentioned fish. M. marinum was detected in all of the most commonly sampled fish species with the exception of C. auratus and X. maculates. Granulomatous lesions suggestive of mycobacteriosis were observed in 5.15\% $(n=7)$ of the fish. Mycobacteria were most frequently isolated from the skin scrapings and contents of digestive tracts, but less frequently from the internal organs (data not shown). A total of 99 mycobacterial isolates were obtained (Tab. 1). The majority of isolates were represented by M. marinum (33.33\%), M. chelonae (16.16\%), M. gordonae (15.15\%), M. peregrinum (12.12\%), and M. fortuitum (10.10\%). Other isolates were identified as $M$. senegalense (4.04\%), M. septicum (2.02\%), M. neoaurum (2.02\%), M. abscessus (1.01\%), M. mucogenicum (1.01\%), M. salmoniphilum (1.01\%), M. saopaulense (1.01\%), and M. szulgai (1.01\%). All the sequences obtained from the $h s p 65$ gene were submitted to the GenBank database under the accession numbers listed in Table 2.

\section{DISCUSSION}

Numerous studies have shown that aquaculture organisms are a source of human bacterial infections $[15,16,17,22]$. Of the bacterial pathogens present in fish and causing human infection, bacteria from the Mycobacterium genus are of great importance. A previous study revealed the occurrence mycobacterial infections in 4 species of ornamental fish [23]. Mycobacterial infections in freshwater African catfish (Clarias gariepinus) were described by Antychowicz et al. [24]. Besides these reports, little is known about mycobacterial infections in fish in Poland.

In the presented study, AFB were detected by microscopy in $15.44 \%$ of the fish and mycobacteria were isolated from $50.74 \%$. Similar results were obtain in Italy by Zanoni et al. [12], who detected AFB in $21.70 \%$ of fish and isolated mycobacteria from $35.9 \%$ of fish. In the Czech Republic, Lescenko et al. [5] detected AFB in $45.70 \%$ of fish and isolated mycobacteria from $70.60 \%$ of fish. In another study carried out in the Czech Republic by Beran et al. [3], AFB were detected in $14.30 \%$ of fish and mycobacteria were isolated from $42.90 \%$ of fish. These researchers also isolated mycobacteria from $75.40 \%$ of environmental samples taken from aquariums. In Sweden, Hongslo et al. [25] detected AFB in $23 \%$ of fish and isolated mycobacteria from $89 \%$ of fish. In Slovenia, Pate et al. [9] detected AFB by microscopy in $37.10 \%$ of fish and isolated mycobacteria from $82.90 \%$ of fish. In India, Shukla et al. [18] isolated mycobacteria from $25 \%$ of examined aquarium fish. One cause of these differences in the NTM smear positivity rates and bacteriology results is the different numbers of mycobacteria in the samples. Other studies support the concept that specimens with low colony counts of mycobacteria are less likely to be detected by smear microscopy [26]. The discrepancy in positive microscopy 
Table 1. Overview of ornamental fish investigated and mycobacteria isolated in this study.

\begin{tabular}{|c|c|c|c|c|c|c|c|c|c|c|c|c|c|c|c|c|}
\hline \multirow[b]{2}{*}{ Fish } & \multirow[b]{2}{*}{ 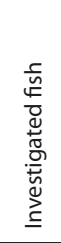 } & \multirow[b]{2}{*}{ 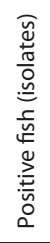 } & \multicolumn{13}{|c|}{ Isolated Mycobacterium } & \multirow[b]{2}{*}{$\begin{array}{l}\tilde{y} \\
\frac{\pi}{0} \\
\stackrel{0}{0} \\
\dot{0}\end{array}$} \\
\hline & & & 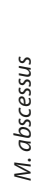 & 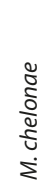 & 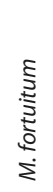 & $\begin{array}{l}\tilde{\Xi} \\
\delta \\
\delta \\
\delta \\
\delta \\
\Sigma\end{array}$ & 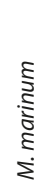 & 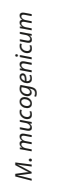 & 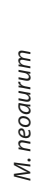 & 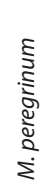 & 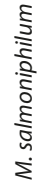 & 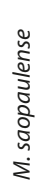 & 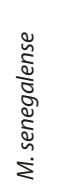 & 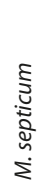 & $\begin{array}{l}\bar{s} \\
\stackrel{\bar{s}}{\bar{N}} \\
\stackrel{\Sigma}{\Sigma}\end{array}$ & \\
\hline Andinoacara pulcher & 1 & 0 & - & - & - & - & - & - & - & - & - & - & - & - & - & 0 \\
\hline Ameiurus nebulosus & 1 & 1 & - & 1 & - & - & - & - & - & - & 1 & - & - & - & - & 2 \\
\hline Ancistrus multispinis & 4 & 3 & - & - & - & - & 3 & - & - & 1 & - & - & - & - & - & 4 \\
\hline Betta splendens & 2 & 1 & - & - & - & - & 1 & - & - & - & - & - & - & - & - & 1 \\
\hline Carassius auratus & 12 & 6 & - & 3 & 1 & 2 & - & - & - & - & - & - & - & - & - & 6 \\
\hline Chromobotia macracanthus & 4 & 1 & - & 1 & - & - & - & - & - & - & - & - & - & - & - & 1 \\
\hline Corydoras punctatus & 1 & 0 & - & - & - & - & - & - & - & - & - & - & - & - & - & 0 \\
\hline Danio rerio & 13 & 8 & - & 1 & 1 & 2 & 4 & - & - & 2 & - & - & 2 & - & - & 12 \\
\hline Epalzeorhynchos bicolor & 1 & 0 & - & - & - & - & - & - & - & - & - & - & - & - & - & 0 \\
\hline Gymnocorymbus ternetzi & 1 & 1 & - & 1 & - & - & - & - & - & - & - & - & - & - & - & 1 \\
\hline Hemigrammus bleheri & 2 & 1 & - & - & 1 & - & - & - & - & - & - & - & - & - & - & 1 \\
\hline Labidochromis caeruleus & 2 & 2 & - & 4 & - & - & - & - & - & 1 & - & - & - & - & - & 5 \\
\hline Macropodus opercularis & 3 & 3 & - & - & 1 & - & 3 & - & - & - & - & - & - & - & - & 4 \\
\hline Macrotocinclus affinis & 1 & 0 & - & - & - & - & - & - & - & - & - & - & - & - & - & 0 \\
\hline Mastacembelus erythrotaenia & 1 & 0 & - & - & - & - & - & - & - & - & - & - & - & - & - & 0 \\
\hline Melanochromis cyaneorhabdos & 2 & 1 & - & 1 & - & - & - & - & - & - & - & - & - & - & - & 1 \\
\hline Mikrogeophagus ramirezi & 3 & 3 & 1 & 1 & - & 1 & 1 & - & - & 1 & - & - & - & - & - & 5 \\
\hline Maylandia zebra & 1 & 0 & - & - & - & - & - & - & - & - & - & - & - & - & - & 0 \\
\hline Nematobrycon palmeri & 1 & 0 & - & - & - & - & - & - & - & - & - & - & - & - & - & 0 \\
\hline Neolamprologus brichardi & 1 & 0 & - & - & - & - & - & - & - & - & - & - & - & - & - & 0 \\
\hline Pangasius sutchi & 1 & 1 & - & - & - & 1 & - & - & - & - & - & - & - & - & - & 1 \\
\hline Paracheirodon innesi & 9 & 4 & - & 1 & 1 & 2 & 1 & - & - & - & - & - & - & - & - & 5 \\
\hline Pangio kuhlii & 1 & 0 & - & - & - & - & - & - & - & - & - & - & - & - & - & 0 \\
\hline Pethia nigrofasciata & 7 & 4 & - & - & - & 2 & 3 & - & - & - & - & - & - & - & - & 5 \\
\hline Pethia ticto & 1 & 1 & - & - & 1 & - & - & - & - & - & - & - & - & - & - & 1 \\
\hline Placidochromis platyrhynchos & 1 & 1 & - & 1 & - & - & - & - & - & 1 & - & - & 1 & - & - & 3 \\
\hline Poecilia reticulata & 12 & 7 & - & - & 1 & 3 & 2 & - & 2 & 1 & - & - & - & - & - & 9 \\
\hline Poecilia sphenops & 8 & 3 & - & - & - & - & 1 & 1 & - & - & - & - & - & - & 1 & 3 \\
\hline Pterophyllum scalare & 8 & 4 & - & 1 & - & - & 3 & - & - & 2 & - & - & 1 & - & - & 7 \\
\hline Symphysodon discus & 3 & 0 & - & - & - & - & - & - & - & - & - & - & - & - & - & 0 \\
\hline Tanichthys albonubes & 1 & 0 & - & - & - & - & - & - & - & - & - & - & - & - & - & 0 \\
\hline Trichogaster Ialius & 3 & 2 & - & - & - & - & 5 & - & - & - & - & - & - & - & - & 5 \\
\hline Trichopodus trichopterus & 4 & 4 & - & - & 2 & 1 & 1 & - & - & 1 & - & 1 & - & - & - & 6 \\
\hline Trigonostigma heteromorpha & 2 & 1 & - & - & - & - & - & - & - & - & - & - & - & 1 & - & 1 \\
\hline Xiphophorus maculatus & 12 & 4 & - & - & 1 & 1 & - & - & - & 2 & - & - & - & 1 & - & 5 \\
\hline Xiphophorus hellerii & 6 & 2 & - & - & - & - & 5 & - & - & - & - & - & - & - & - & 5 \\
\hline Total & 136 & 69 & 1 & 16 & 10 & 15 & 33 & 1 & 2 & 12 & 1 & 1 & 4 & 2 & 1 & 99 \\
\hline
\end{tabular}

results and bacteriology results could also relate in part to the differences in acid-alcohol-fastness, which tends to be a stronger attribute in slow-growing mycobacteria [27].

All 13 species of mycobacteria isolated in the present study were previously isolated from ornamental fish. In the Czech Republic, studies on the occurrence of mycobacteria in aquarium fish were conducted by Lescenko et al. [5] in which the isolated mycobacteria were represented by the species $M$. marinum, M. gordonae, $M$. triviale, and M. avium subsp. hominissuis. Similar studies, also in the Czech Republic, were conducted by Beran et al. [3], who isolated M. fortuitum, $M$. flavescens, $M$. chelonae, $M$. gordonae, $M$. terrae, $M$. triviale, $M$. diernhoferi, M. celatum, M. kansasii, and M. intracellulare. The most frequently isolated mycobacteria were $M$. fortuitum, 
Table 2. Mycobacterium strains identified by sequencing of $h s p 65$ PCR products. M. abscessus (M. a.), M. chelonae (M. c.), M. fortuitum (M. f.), M. gordonae (M. g.), M. marinum (M. m.), M. mucogenicum (M. muc.), M. neoaurum (M. n.), M. peregrinum (M. p.), M. salmoniphilum (M. sal.), M. saopaulense (M. sao.), M. senegalense (M. sen.), M. septicum (M. sep.), M. szulgai (M. sz.)

\begin{tabular}{|c|c|c|c|c|c|c|c|}
\hline Species & Strain & Accession No. & Source & Species & Strain & Accession No. & Source \\
\hline M. $a$. & M11 & KX231724 & M. ramirezi & M. $m$ & M21 & KX231690 & T. Ialius \\
\hline M. c. & M2 & KX231726 & L. caeruleus & M. $m$ & M26 & KX231691 & A. multispinis \\
\hline M. c. & M8 & KX231727 & P. scalare & M. $m$ & M46 & KX231692 & A. multispinis \\
\hline M.c. & M23 & KX231729 & C. auratus & M. $m$ & M47 & KX231693 & A. multispinis \\
\hline M. c. & M34 & KX231730 & C. auratus & M. $m$ & M48 & KX231694 & P. reticulata \\
\hline M. c. & M36 & KX231731 & C. auratus & M. $m$ & M50 & KX231695 & P. sphenops \\
\hline M.c. & M37 & KX231732 & A. nebulosus & M. $m$ & M55 & KX231698 & D. rerio \\
\hline M.c. & M40 & KX231733 & M. cyaneorhabdos & M. $m$ & M56 & KX231699 & D. rerio \\
\hline M. c. & M83 & KX231735 & D. rerio & M. $m$ & M58 & KX231700 & M. ramirezi \\
\hline M.c. & M94 & KX231736 & G. ternetzi & M. $m$ & M60 & KX231702 & M. opercularis \\
\hline M. c. & M97 & KX231737 & P. platyrhynchos & M. $m$ & M62 & KX231703 & B. splendens \\
\hline M. c. & M100 & KX231738 & L. caeruleus & M. $m$ & M70 & KX231706 & M. opercularis \\
\hline M. c. & M101 & KX231739 & L. caeruleus & M. $m$ & M72 & KX231707 & D. rerio \\
\hline M. c. & M102 & KX231740 & L. caeruleus & M. $m$ & M90 & KX231708 & T. trichopterus \\
\hline M.c. & M12 & KX244857 & C. macracanthus & M. $m$ & M53 & KX231696 & P. nigrofasciata \\
\hline M. c. & M18 & KX231728 & P. innesi & M. $m$ & M54 & KX231697 & P. innesi \\
\hline M. c. & M57 & KX231734 & M. ramirezi & M. $m$ & M59 & KX231701 & D. rerio \\
\hline M.f. & M7 & KX244856 & P. reticulata & M. $m$ & M67 & KX231704 & P. nigrofasciata \\
\hline M. f. & M14W & KX231765 & M. opercularis & M. $m$ & M68 & KX231705 & P. nigrofasciata \\
\hline M. $f$. & M17 & KX231766 & P. innesi & M. $m$ & M42 & KX231751 & X. maculatus \\
\hline M. $f$. & M22 & KX244858 & H. bleheri & M. $m$ & M43 & KX231752 & $X$. maculatus \\
\hline M. f. & M29 & KX231767 & C. auratus & M. $m$ & M49 & KX231753 & P. reticulata \\
\hline M. f. & M52 & KX231768 & X. maculatus & M. $m$ & M63 & KX231754 & P. scalare \\
\hline M. f. & M81 & KX231769 & D. rerio & M. $m$ & M64 & KX231755 & P. scalare \\
\hline M. f. & M88 & KX231770 & T. trichopterus & M. $m$ & M84 & KX231756 & P. scalare \\
\hline M. $f$. & M91 & KX231771 & P. ticto & M. muc. & M6 & KX244855 & P. nigrofasciata \\
\hline M.f. & M92 & KX231772 & T. trichopterus & M. $n$. & M75 & KX244862 & P. reticulata \\
\hline M. $g$. & M25 & KX231711 & C. auratus & M. $n$. & M76 & KX244863 & P. reticulata \\
\hline M. $g$. & M27 & KX231712 & P. sutchi & M.p. & M24 & KX231742 & M. ramirezi \\
\hline M. $g$. & M28 & KX231713 & P. reticulata & M.p. & M45 & KX231743 & D. rerio \\
\hline M. $g$. & M30 & KX231714 & P. innesi & M. p. & M71 & KX231744 & A. multispinis \\
\hline M. $g$. & M61 & KX244861 & C. auratus & M. p. & M79 & KX231745 & D. rerio \\
\hline M. $g$. & M66 & KX231719 & X. maculatus & M. p. & M82 & KX231746 & X. maculatus \\
\hline M. $g$. & M19 & KX231709 & D. rerio & M. $p$. & M98 & KX231749 & P. scalare \\
\hline M. $g$. & M20 & KX231710 & D. rerio & M. p. & M99 & KX231750 & P. scalare \\
\hline M. $g$. & M31 & KX231715 & T. trichopterus & M. p. & M73 & KX231758 & P. reticulata \\
\hline M. $g$. & M32 & KX231716 & M. ramirezi & M. p. & M78 & KX231759 & X. maculatus \\
\hline M. $g$. & M33 & KX231717 & C. auratus & M. p. & M96 & KX231748 & P. platyrhynchos \\
\hline M. $g$. & M65 & KX231718 & P. nigrofasciata & M. p. & M1 & KX231741 & L. caeruleus \\
\hline M. $g$. & M85 & KX231720 & P. reticulata & M. p. & M93 & KX231747 & T. trichopterus \\
\hline M. $g$. & M86 & KX231721 & P. reticulata & M. sal. & M39 & KX244859 & A. nebulosus \\
\hline M. $g$. & M87 & KX231722 & P. nigrofasciata & M. sao. & M89 & KX231725 & T. trichopterus \\
\hline M. $m$ & M3 & KX231683 & T. Ialius & M. sen. & M74 & KX231761 & P. scalare \\
\hline M. $m$ & M4 & KX231684 & T. Ialius & M. sen. & M95 & KX231762 & P. platyrhynchos \\
\hline M. $m$ & M9 & KX231685 & $X$. hellerii & M. sen. & M80 & KX231763 & D. rerio \\
\hline M. $m$ & M10 & KX231686 & $X$. hellerii & M. sen. & M41 & KX231764 & D. rerio \\
\hline M. $m$ & M13 & KX231687 & $X$. hellerii & M. sep. & M51 & KX244860 & T. heteromorpha \\
\hline M. $m$ & M14 & KX231757 & M. opercularis & M. sep. & M77 & KX231760 & X. maculatus \\
\hline M. $m$ & M15 & KX231688 & T. Ialius & M. sz. & M69 & KX231723 & P. sphenops \\
\hline M. $m$ & M16 & KX231689 & T. Ialius & & & & \\
\hline
\end{tabular}


M. flavescens, M. chelonae. However, they did not isolate M. marinum, i.e. a species that was most frequently identified in the presented study. However, in studies carried out in Sweden by Hongslo et al. [25], the most frequently isolated species was Mycobacterium marinum, followed by M. chelonae and $M$. gordonae. In Italy, Zanoni et al. [12] isolated M. fortuitum, M. peregrinum, M. chelonae, M. abscessus, M. marinum, M. gordonae, $M$. nonchromogenicum, and $M$. interjectum. The most frequently isolated mycobacteria were $M$. fortuitum, $M$. peregrinum, and $M$. chelonae. In India, Shukla et al. [18] isolated M. abscessus, M. gordonae, $M$. fortuitum, M. conceptionense, M. parascrofulaceum, and $M$. senegalense. The most frequently isolated mycobacteria were $M$. abscessus and M. gordonae.

The difference in the prevalence of mycobacteria among different countries could relate to the endemic occurrence of certain species of mycobacteria in water-supply systems. For example, the Czech Republic is a country with an endemic incidence of $M$. kansasii in water [3]. The variation in prevalence may also depend on the fish supplier. Smith et al. [28] suggest that cleaning regimes, filtration, or handling procedures influence the diversity of bacteria within the tanks. The differences in the mycobacterial isolation rate may also depend on the diversity of fish species from which samples were taken. Numerous species of ornamental fish have been reported with mycobacterial infections; however, some species appear to be more susceptible and therefore demonstrate a higher incidence of infections [12].

The present study has shown that aquarium fish are a source of mycobacteria, which are potentially pathogenic for both fish and humans. It is noteworthy that M. marinum, i.e. the most frequently isolated species in this work, causes most cases of fish-related mycobacterial infection in humans.

\section{Cconflict of interest}

The authors declare that they have no competing interests.

\section{REFERENCES}

1. Gauthier DT, Rhodes MW. Mycobacteriosis in fishes: A review. The Vet J. 2009; 180: 33-47.

2. Decostere A, Hermans K, Haesebrouck F. Piscine mycobacteriosis: A literature review covering the agent and the disease it causes in fish and humans. Vet Microbiol. 2004; 99: 159-166.

3. Beran V, Matlova L, Dvorska L, Svastova P, Pavlik I. Distribution of mycobacteria in clinically healthy ornamental fish and their aquarium environment. J Fish Dis. 2006; 29: 383-393.

4. Guz L, Grądzki Z, Krajewska M, Lipiec M, Zabost A, AugustynowiczKopeć E, Zwolska Z, Szulowski K. Occurrence and antimicrobial susceptibility of Mycobacterium peregrinum in ornamental fish. Bull Vet Ins Pulawy 2013; 57: 489-492.

5. Lescenko P, Matlova L, Dvorska L, Bartos M, Vavra O, Navratil S, Novotny L, Pavlik I. Mycobacterial infection in aquarium fish. Vet Med.(Praha) 2003; 48: 71-78.

6. Levi MH, Bartell J, Gandolfo L, Smole SC, Costa SF, Weiss LM, Johnson LK, Osterhout G, Herbst LH. Characterization of Mycobacterium montefiorense sp. nov., a novel pathogenic Mycobacterium from moray eels that is related to Mycobacterium triplex. J Clin Microbiol. 2003; 41:2147-2152.

7. Marumo K, Nakamura H, Tarawa S, Kazumi Y, Kawano R, Shirata C, Taguchi K, Kikuchi T, Nagashima G. Isolation of novel mycobacteria contaminating an aquarium fish tank in a Japanese university hospital. J Appl Microbiol. 2010; 109: 558-566.

8. Nogueira CL, Whipps CM, Matsumoto CK, Chimara E, Droz S, Tortoli E, Freitas DD, Cnockaert M, Palomino JC, Martin A, Vandamme
P, Leão SC. Mycobacterium saopaulense sp. nov., a rapidly growing mycobacterium closely related to members of the Mycobacterium chelonae-Mycobacterium abscessus group. Int J Syst Evol Microbiol. 2015; 65: 4403-4409.

9. Pate M, Jencic V, Zolnir-Dovc M, Ocepek M. Detection of mycobacteria in aquarium fish in Slovenia by culture and molecular methods. Dis Aquat Org. 2005; 64: 29-35.

10. Rhodes MW, Kator H, Kotob S, van Berkum P, Kaattari I, Vogelbein W, Quinn F, Floyd MM, Butler WR, Ottinger CA. Mycobacterium shottsii sp. nov., a slowly growing species isolated from Chesapeake Bay striped bass (Morone saxatilis). Int J Syst Evol Microbiol. 2003; 53: 421-424.

11. Whipps CM, Dougan ST, Kent ML. Mycobacterium haemophilum infections of zebrafish (Danio rerio) in research facilities. FEMS Microbiol Lett. 2007; 270: 21-26.

12. Zanoni RG, Florio D, Fioravanti ML, Rossi M, Prearo M. Occurrence of Mycobacterium spp. in ornamental fish in Italy. J Fish Dis. 2008; 31: 433-441.

13. Zerihun MA, Berg V, Lyche JL, Colquhoun DJ, Poppe TT. Mycobacterium salmoniphilum infection in burbot Lota lota. Dis Aquat Org. 2011; 95 : 57-64.

14. Strike TB, Feltrer Y, Flach E, Macgregor SK, Guillaume S. Investigation and management of an outbreak of multispecies mycobacteriosis in Australian lungfish (Neoceratodus fosteri) including the use of triple antibiotic treatment. J Fish Dis. 2017; 40: 557-570.

15. Bhatty MA, Turner DP, Chamberlain ST. Mycobacterium marinum hand infection: case reports and review of literature. Brit J Plast Surg. 2000; 53: 161-165.

16. Dodiuk-Gad R, Dyachenko P, Ziv M, Shani-Adir A, Oren Y, Mendelovici S, Shafer J, Chazan B, Raz R, Keness Y, Rozenman D. Nontuberculous mycobacterial infections of the skin: a retrospective study of 25 cases. J Am Acad Dermatol. 2007; 57: 413-420.

17. Talavlikar R, Carson J, Meatherill B, Desai S, Sharma M, Shandro C, Tyrrell GJ, Kuhn S. Mycobacterium senegalense tissue infection in a child after fish tank exposure. Can J Infect Dis Med Microbiol. 2011; 22: 101-103.

18. Shukla S, Shukla SK, Sharma R, Kumar A. Identification of Mycobacterium species from apparently healthy freshwater aquarium fish using partial sequencing and PCR-RFLP analysis of heat shock protein (hsp65) gene. J Appl Ichthyol. 2014; 30: 513-520.

19. Wallace RJ, Jr, Iakhiaeva E, Williams MD, Brown-Elliott BA, Vasireddy S, Vasireddy R, Lande L, Peterson DD, Sawicki J, Kwait R, Tichenor WS, Turenne C, Falkinham JO. Absence of Mycobacterium intracellulare and presence of Mycobacterium chimaera in household water and biofilm samples of patients in the United States with Mycobacterium avium complex respiratory disease. J Clin Microbiol. 2013; 51: 1747-1752.

20. Kim SH, Shin JH. Identification of nontuberculous mycobacteria using multilocous sequence analysis of $16 \mathrm{~S}$ rRNA, $h s p 65$, and $r p o B$. J Clin Lab Anal. 2018; 32: e22184.

21. Telenti A, Marchesi F, Balz M, Bally F, Bottger EC, Bodmer T. Rapid identification of mycobacteria to the species level by polymerase chain reaction and restriction enzyme analysis. J Clin Microbiol. 1993; 31: $175-178$.

22. Novotny L, Dvorska L, Lorencova A, Beran V, Pavlik I. Fish: A potential source of bacterial pathogens for human beings. Vet Med. (Praha) 2004; 9: 343-358.

23. Puk K, Banach T, Wawrzyniak A, Adaszek Ł, Ziętek J, Winiarczyk $\mathrm{S}$, Guz L. Detection of Mycobacterium marinum, M. peregrinum, $M$. fortuitum and M. abscessus in aquarium fish. J Fish Dis. 2018; 41: $153-156$.

24. Antychowicz J, Lipiec M, Matusiewicz J. Infection of African catfish (Clarias gariepinus) in an intensive culture facility Mycobacterium marinum. Bull Eur Ass Fish Pathol. 2003; 23: 60-66.

25. Hongslo T, Jansson E. Occurrence of different species of mycobacteria in aquarium fish from Swedish pet-shops. Bull Eur Ass Fish Pathol. 2014; 34: 78-86.

26. Pollock HM, Wieman EJ. Smear results in the diagnosis of mycobacterioses using blue light fluorescence microscopy. J Clin Microbiol. 1977; 5: 329-331.

27. Wright PW, Wallace RJ Jr., Wright NW, Brown BA, Griffith DE. Sensitivity of fluorochrome microscopy for detection of Mycobacterium tuberculosis versus nontuberculous mycobacteria. J Clin Microbiol. 1998; 36: 1046-1049.

28. Smith KF, Schmidt V, Rosen GE, Amaral-Zettler L. Microbial Diversity and Potential Pathogens in Ornamental Fish Aquarium Water. PLOS ONE 2012; 7:e39971. 